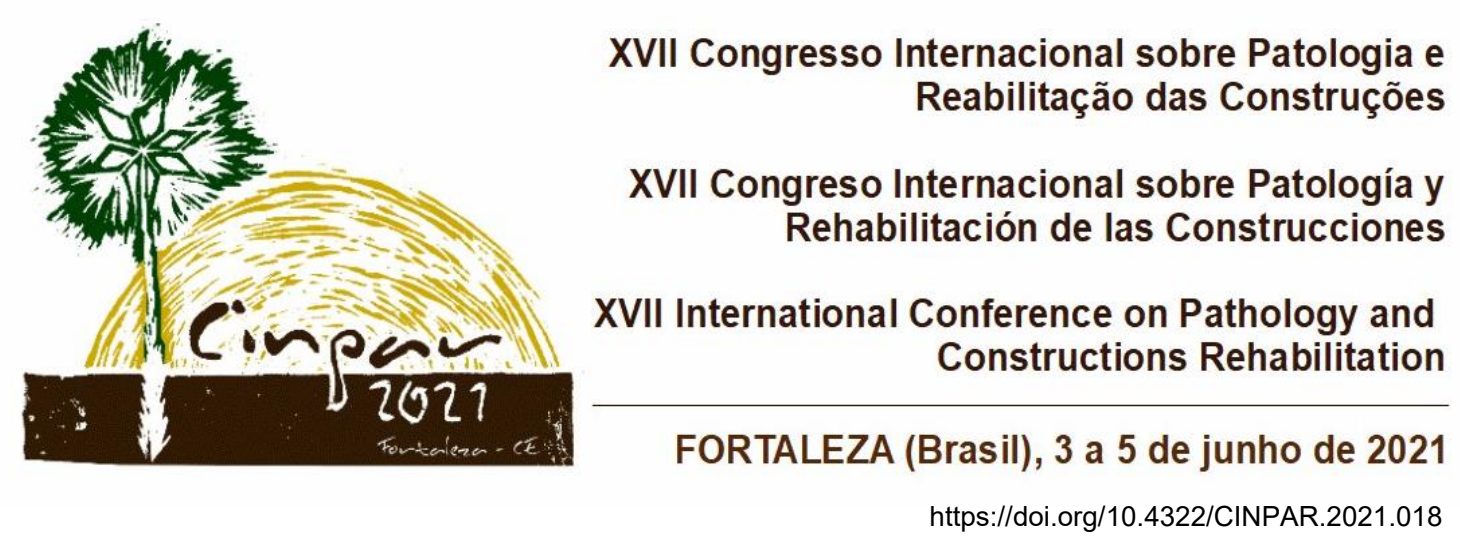

\title{
Estudo da evolução das patologias causadas por umidade na edificação da Universidade Federal de São João del Rei - Campus Alto Paraopeba
}

\section{Study of the evolution of pathologies caused by humidity in the building of the Federal University of São João del Rei - Campus Alto Paraopeba}

\author{
Lorena AGUILAR ${ }^{1}$, Marina BRÍGIDA², Marina DONATO³ ${ }^{3}$ Débora SANTOS ${ }^{4}$, José BORBA JR \\ ${ }^{1}$ Universidade Federal de São João del Rei, Ouro Branco, Brasil, lorenaoz.aguilar@gmail.com \\ 2 Universidade Federal de São João del Rei, Ouro Branco, Brasil, oks.marina@gmail.com \\ ${ }^{3}$ Universidade Federal de São João del Rei, Ouro Branco, Brasil, donato@ufsj.edu.br \\ ${ }^{4}$ Universidade Federal de São João del Rei, Ouro Branco, Brasil, deboradavilasantos@gmail.com \\ ${ }^{5}$ Universidade Federal de São João del Rei, Ouro Branco, Brasil, joseborba@ufsj.edu.br
}

\begin{abstract}
Resumo: O concreto é amplamente utilizado no ramo da construção civil, no entanto, suas propriedades intrínsecas podem induzir as manifestações patológicas. Desta forma, é importante e vem crescendo cada vez mais a busca por tecnologias que melhorem seu desempenho e proporcione uma maior vida útil. 0 presente trabalho tem como objetivo geral identificar e classificar problemas ocasionados por manifestações patológicas decorrentes de umidade nas edificações, demonstrando a maneira de se inspecionar visando mecanismos de proteção, manutenção e restauração das estruturas afetadas. Este estudo se refere a edificação destinada a Universidade Federal de São João Del Rei - Campus Alto Paraopeba no município de Ouro Branco-MG. O processo é realizado de forma a inspecionar e, através do levantamento de dados, classifica-las conforme um referencial teórico que auxilie no desenvolvimento do tema. No decorrer dessa pesquisa foram analisadas as manifestações por inspeção visual da edificação, de acordo com a norma do IBAPE (2012) visando identificar as causas e classifica-las de acordo com o seu grau de periculosidade. Em segundo momento, o trabalho apresenta uma análise criteriosa de toda a informação coletada do edifício. A conclusão do trabalho se fundamenta no aprimoramento dos quesitos de vistorias com um olhar crítico, visando a importância da manutenção e preservação das edificações, evitando possíveis ocorrências de patologias que possam vir a danificar as estruturas.
\end{abstract}

Palavras-chave: patologia; umidade; edificações; inspeção; vistoria.

\begin{abstract}
Concrete is widely used in the field of civil construction, however, its intrinsic properties can induce pathological manifestations. In this way, it is important and is growing increasingly the search for technologies that improve its performance and provide a longer service life. The present work has as general objective to identify and classify problems caused by pathological manifestations resulting from moisture in buildings, demonstrating the way to inspect aiming at mechanisms of protection, maintenance and restoration of the affected structures. This study refers to the building destined to the Federal University of São João Del Rei - Campus Alto Paraopeba in the municipality of Ouro Branco-MG. The process
\end{abstract}


is carried out in order to inspect and, through data collection, classify them according to a theoretical framework that helps in the development of the theme. During this research, the manifestations by visual inspection of the building were analyzed, according to the IBAPE standard (2012) in order to identify the causes and classify them according to their degree of dangerousness. Secondly, the work presents a careful analysis of all information collected from the building. The conclusion of the work is based on the improvement of the requirements of surveys with a critical view, aiming at the importance of maintaining and preserving buildings, avoiding possible occurrences of pathologies that may damage the structures.

Keywords: pathology; humidity; buildings; inspection; survey.

\section{Introdução}

A construção civil no Brasil tem sofrido grandes avanços e mudanças ao longo das últimas décadas. Nos últimos anos o Brasil tem enfrentado uma das suas piores crises da construção civil. Atualmente, observamos que o leve crescimento do país impulsiona novas oportunidades de investimentos nessa área, a geração de empregos de renda direta e indireta e a retomada de uma grande competitividade entre as incorporadoras e construtoras do país.

As construções, mesmo que em ótimo estado tem uma vida útil e, para que essa vida útil seja atendida e/ou superada devem haver manutenções periódicas para a sua conservação. Mesmo com as prevenções, as estruturas podem ser afetadas tanto por sua utilização, como por agentes agressivos presentes no ambiente.

As manifestações patológicas são inúmeras, assim, torna-se essencial uma análise minuciosa dos dados a serem coletados através de inspeções realizadas. Estas análises permitem um melhor entendimento do problema e a busca adequada para soluções.

Visando a importância do estudo das manifestações patológicas para o crescimento profissional, foi realizado um estudo de caso para identificar e analisar a progressão das principais patologias causadas por umidade presentes na edificação da Universidade Federal de São João Del Rei do Campus Alto do Paraopeba localizada entre os municípios de Ouro Branco e Congonhas em Minas Gerais.

\section{Revisão da Literatura}

\subsection{Patologias de umidade na construção}

A vida útil de uma edificação consiste em mensurar a expectativa de duração de uma estrutura ou suas partes, dentro de limites de projeto admissíveis, durante seu ciclo de vida (POSSAN e DEMOLINER, 2013; BOLINA et al., 2019). De acordo com a ISO 13823 (2008) o período efetivo de tempo durante o qual uma estrutura ou qualquer de seus componentes satisfazem os requisitos de desempenho do projeto, sem ações imprevistas de manutenção ou reparo.

Segundo Souza e Ripper (1998), a área de estudo da Patologia das Estruturas é um novo campo da Engenharia das Construções que se ocupa do estudo das origens, formas de manifestação, consequências e mecanismos de ocorrência das falhas e dos sistemas de degradação das estruturas.

\subsubsection{Umidade}

Segundo Souza (2008), na construção civil, os defeitos mais comuns decorrem da penetração de água ou da formação de manchas de umidade, que podem ocasionar problemas graves de difíceis soluções como: prejuízos de caráter funcional da edificação, desconforto dos usuários com risco de terem a saúde afetada, danos em equipamentos e bens no interior das edificações e prejuízos financeiros.

As causas da umidade nas edificações, segundo Lersch (2003), são: umidade de infiltração; umidade ascensional; umidade por condensação; umidade de obra; umidade acidental. 
A umidade passa das áreas externas às internas por pequenas trincas, pela alta capacidade de os materiais absorverem a umidade do ar ou mesmo por falhas na interface entre elementos construtivos, como planos de parede e portas ou janelas. Em geral, é ocasionada pela água da chuva e, se combinada com o vento, pode agravar a infiltração com o aumento da pressão de infiltração (RIGHI, 2009; CECHINEL et al., 2021).

b) Umidade ascensional

A umidade, em questão, é oriunda de água do solo, que tende a ascender e atinge a edificação.

Para Queruz (2007), esse fenômeno de ascensão é consequência da capilaridade, na qual os vasos capilares, pequenos canais vazios existentes em diversos materiais como cerâmicos e lenhosos, permitem que a água suba até o momento em que entra em equilíbrio com a força da gravidade.

c) Umidade por condensação

Caracteriza-se por ser resultado da presença de grande umidade no ar e da existência de superfícies que estejam com temperatura abaixo da correspondente ao ponto do orvalho. O fenômeno ocorre pela redução de capacidade de absorção de umidade pelo ar quando é resfriado, na interface da parede, precipitando-se (RIGHI, 2009).

Segundo a conclusão de Kluppel e Santana (2006) (apud QUERUZ, 2007), esse tipo de agente costuma apresentar-se de forma superficial, sem penetrar a grandes profundidades. Pode-se salientar, inclusive, que os diferentes materiais, de acordo às suas densidades, se comportam de forma diferenciada quanto à condensação, os mais densos sofrem mais com o fenômeno (RIGHI, 2009; CECHINEL et al., 2021).

d) Umidade de obra

A umidade de obra é a quantidade de umidade presente em uma edificação após o término das atividades da obra, a qual tende a desaparecer gradualmente (LERSCH, 2003; OLIVEIRA, 2013; CECHINEL et al., 2021). Segundo Queruz (2007), caracteriza-se como a umidade que ficou interna aos materiais devido à sua execução e em decorrência do equilíbrio que se estabelece entre o material e o ambiente, ela se exterioriza.

O exemplo mais comum desse tipo de situação é a umidade contida nas argamassas de reboco que, logo após executadas, transferem o excesso de umidade para a parte interna das alvenarias, necessitando de um prazo maior do que o da cura do próprio reboco para entrar em equilíbrio com o ambiente em que está situada (QUERUZ, 2007; CECHINEL et al., 2021).

e) Umidade acidental

É a umidade causada por falhas nos sistemas de tubulações, como águas pluviais, esgoto e água potável, e que geram infiltrações (RIGHI, 2009).

A existência de umidade com esse tipo de origem adquire importância especial quando se trata de edificações que já possuem um longo período de existência. Tal fato decorre da presença de materiais que podem ter seu tempo de vida já excedido, como antigas tubulações (dutos de ferro fundido para água potável ou manilhas cerâmicas para águas servidas), que não costumam ser contempladas em planos de manutenção predial (QUERUZ, 2007; CECHINEL et al., 2021).

\subsubsection{Manifestações Patológicas}

O surgimento de problemas patológicos em uma estrutura está relacionado a diversos fatores, sendo muitas vezes decorrência de um conjunto destes que acabam por desencadear anomalias na edificação. É de grande importância o conhecimento destes fatores, pois para se determinar que medidas devam ser tomadas diante de uma estrutura que apresenta alguma manifestação patológica, faz-se necessário conhecer o correto diagnóstico dessa anomalia, para poder agir de forma eficiente, proporcionando uma recuperação adequada ao tipo de problema apresentado (TUTIKIAN e PACHECO, 2013). Pode-se analisar pela Figura 1 os meios de manifestações patológicas. 


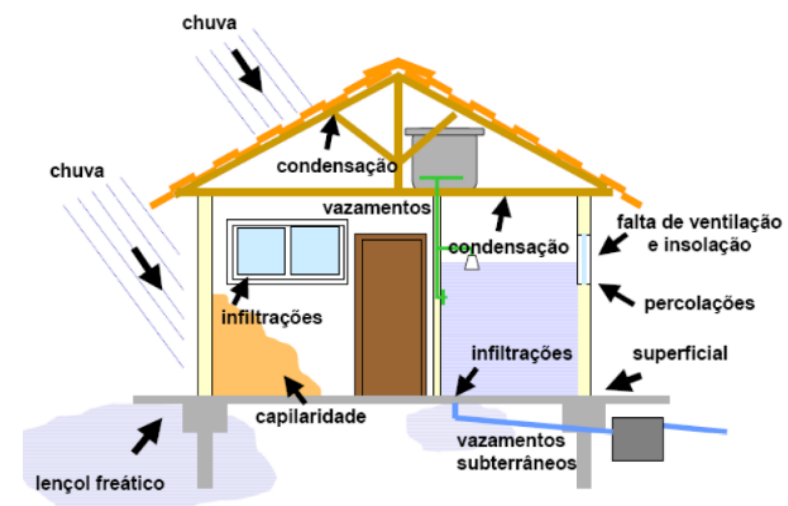

Figura 1 - Ação da umidade (POZZOBON, 2007 apud SCHEIDEGGER e CALENZANI, 2019).

De acordo Verçoza (1987) apud Schönardie (2009), a ausência de impermeabilizantes nas áreas molhadas pode causar, os seguintes problemas: goteiras e manchas; mofo e bolor; corrosão da armadura; eflorescências; saponificação; desagregamento; bolhas; destacamento.

\subsection{Inspeção}

Segundo SOUZA e RIPPER (1998), descreve-se por inspeção o método de examinar com atenção, sendo a inspeção uma análise criteriosa em conjunto com procedimentos padronizados e técnicos que auxiliam na detecção de riscos e/ou problemas a serem manifestados, no nosso caso as patologias nas construções civil. $\mathrm{O}$ ato de inspecionar proporciona a implementação de intervenções objetivando a contenção e/ou manutenção de possíveis danos a estrutura.

A inspeção proporciona traçar metodologias que garantam a solução de patologias existentes e que possam vir a ocorrer, podendo-se definir com o levantamento de informações, compreendendo em dados suficientes para o entendimento do problema a ser tratado, essas informações são previamente coletadas com vistorias em edificações para identificação de problemas e/ou sintomas patológicos gerado em seu histórico.

a) Inspeção preliminar

A fase de inspeção preliminar tem como objetivo determinar através da análise visual juntamente com o histórico da edificação, se a estrutura apresenta necessidade de ter uma intervenção imediatamente. Estima-se nessa inspeção as consequências possíveis que os danos podem trazer e, caso seja necessário, as medidas de emergência que poderão ser tomadas para tal estrutura. Baseando-se nas informações obtidas deste processo, também é possível seguir para um estudo a fundo e mais detalhado (SCHÖNARDIE, 2009).

b) Inspeção detalhada

A etapa de inspeção detalhada deve ser executada por profissionais e consiste na definição da causa da manifestação patológica encontrada em uma determinada estrutura de concreto. Isto será possível através da realização de ensaios de campo e de laboratório para que seja alcançado um diagnóstico coerente e sendo assim, efetuar intervenções precisas (SCHÖNARDIE, 2009).

\section{Metodologia}

O estudo aborda a evolução dos problemas de patologias por umidade, na edificação designada à Universidade Federal de São João Del Rei, Campus Alto Paraopeba, localizada entre os municípios de Ouro Branco e Congonhas na Rodovia MG 443, Km 7. A Figura 2 apresenta a metodologia simplificada utilizada.

Uma inspeção preliminar foi realizada para identificação dos processos patológicos presentes na edificação, sem a intenção de catalogar ou investigar as causas. Posteriormente, foi feita outra vistoria, em duas etapas, identificando todos os pontos atingidos pela ação da umidade no prédio destinado às salas de aula e, depois nas demais dependências da universidade. Comparou-se a evolução de pontos já notados há anos atrás e acrescentaram-se focos novos da patologia. Destaca-se que todo o trabalho foi desenvolvido a 
partir das instruções normativas pertinentes e, ao momento de identificação das manifestações patológicas, já foram previstas suas possíveis causas e classificações quanto ao seu grau de periculosidade para a estrutura.

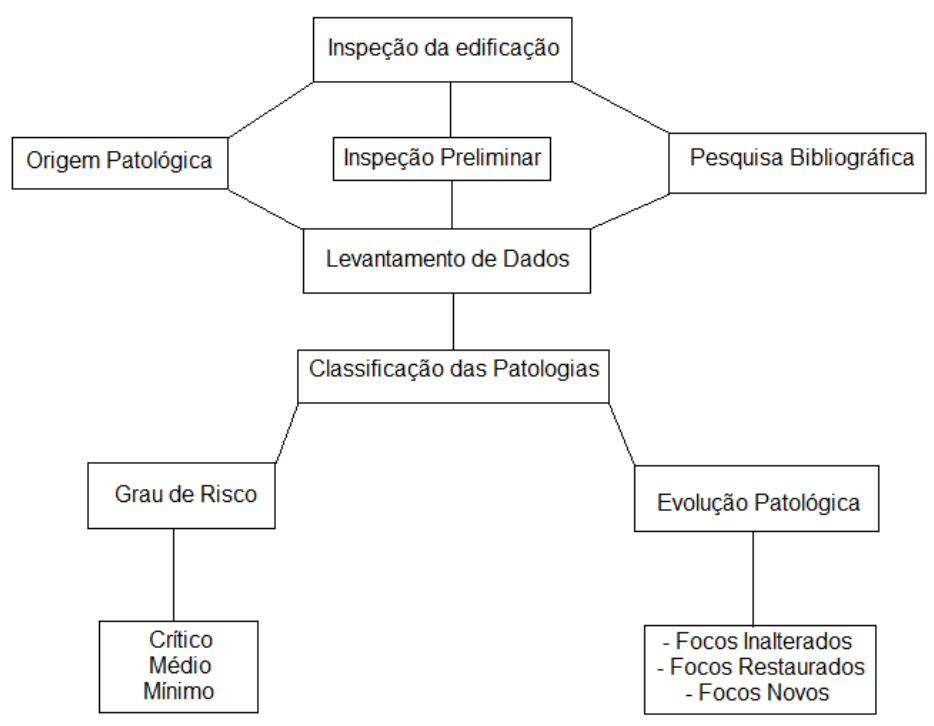

Figura 2 - Metodologia Simplificada

Os dados levantados, por meio de registros fotográficos e anotações, foram analisados e diagnosticados de acordo com o referencial teórico, abordado no trabalho. Esse diagnóstico foi qualitativo e quantitativo, sendo a classificação realizada de acordo com a Norma de Inspeção Predial Nacional do IBAPE - Instituto Brasileiro de Avaliações e Perícias de Engenharia (2012), que classifica a inspeção como a análise isolada ou combinada das condições técnicas, de uso e manutenção da edificação.

A inspeção pode ser feita em 3 níveis, variando de baixa complexidade a alta complexidade, considerando as características técnicas da edificação, manutenção e operação existentes.

Realizou-se a inspeção do nível 1 com baixa complexidade técnica, de manutenção e de operação de seus elementos e sistemas construtivos.

Sendo a do nível 1 realizada em edificações com baixa complexidade técnica, de manutenção e de operação de seus elementos e sistemas construtivos. Normalmente empregada em edificações com planos de manutenção muito simples ou inexistentes.

Feito isso, define-se o critério da inspeção. O critério consiste na análise do risco oferecido aos usuários, ao meio ambiente e ao patrimônio, diante das condições técnicas, de uso, operação e manutenção da edificação, bem como da natureza da exposição ambiental. Essa análise de risco consiste na classificação das anomalias e falhas identificadas podendo ser a anomalia endógena, exógena, natural ou funcional e, as falhas podem ser decorrentes de planejamento, de execução, operacionais ou gerenciais, que se relaciona com fatores de manutenção, depreciação, saúde, segurança, funcionalidade, comprometimento de vida útil e perda de desempenho.

Efetua-se, desse modo, a classificação quanto ao grau de risco que deve ser fundamentado conforme limites e os níveis da Inspeção Predial realizada. Leva-se em consideração o grau de risco oferecido aos usuários, ao meio ambiente e ao patrimônio. E, a classificação das anomalias e falhas.

Em relação à resistência da estrutura, as patologias foram classificadas, de acordo IBAPE (2012), em:

a) Risco crítico: risco de provocar danos contra a saúde e segurança das pessoas e do meio ambiente; perda excessiva de desempenho e funcionalidade causando possíveis paralisações; aumento excessivo de custo de manutenção e recuperação; comprometimento sensível de vida útil.

b) Risco médio: risco de provocar a perda parcial de desempenho e funcionalidade da edificação sem prejuízo à operação direta de sistemas, e deterioração precoce. 
c) Risco mínimo: risco de causar pequenos prejuízos à estética ou atividade programável e planejada, sem incidência ou sem a probabilidade de ocorrência dos riscos críticos e regulares, além de baixo ou nenhum comprometimento do valor imobiliário.

Esse método, além de ser normativo, é adotado para muitas pesquisas sobre patologias nas edificações. Mas apresenta algumas falhas, pois é uma forma dedutiva de diagnosticá-las e, devido a ausência do projeto original da edificação e dos dados relativos às manutenções realizadas, não pôde haver uma pesquisa aprofundada sobre a causa das manifestações patológicas e se houve uma restauração eficaz quanto às reformas que foram efetuadas.

\section{$4 \quad$ Resultados e discussão}

Com a metodologia demonstrada, realizou-se uma visita a edificação e utilizando-se da inspeção preliminar pode-se determinar através de uma análise visual juntamente com o histórico da edificação, as possíveis intervenções a serem realizadas na estrutura e a classificação do seu risco.

Com o levantamento das manifestações patológicas recorrentes de umidade, elaborou-se assim com os dados coletados um mapa de danos, foi definido o procedimento de anexar à planta do edifício, pontos onde existem sinais de danos referentes às manifestações recorrentes a umidade, estes pontos foram sinalizados e classificados para uma melhor localização, conforme demonstrado na Figura 3 e Figura 4 referentes ao primeiro e segundo pavimento, que proporcionou estabelecer uma melhor visualização de toda edificação.

Esse mapeamento proporcionou a identificação e classificação das manifestações patológicas por umidade de acordo com a revisão da literatura já demonstrada, sendo as seguintes: manchas, descascamento da pintura, saponificação, goteira, eflorescência, bolhas, corrosão da armadura, descolamento da cerâmica, desagregamento do revestimento e mofo.

Dentre as manisfestações identificadas na torre 2, no teto do banheiro masculino do primeiro piso (Figura 3), recorrentes a umidade acidental como saponificação, desagregamento da pintura e manchas (Figura 5). Identificou-se na torre 4, no banheiro masculino do primeiro piso (Figura 3), manifestações recorrentes a umidade por infiltração e umidade ascensional causando destacamento da cerâmica (Figura 6). Observouse no bloco 4, primeiro piso (Figura 3) o desagregamento e bolhas (Figura 7), devido à umidade ascensional. No Bloco 5, segundo piso (Figura 4), observou-se as consequências da umidade por condensação, através de eflorescência, saponificação, mofo e bolor (Figura 8) no teto no segundo andar.

Logo, a manifestação patológica com maior índice de incidência na edificação da Universidade Federal de São João del Rei - Campus Alto Paraopeba, se dá por problemas provenientes de umidade. Percebe-se ainda que, o maior problema é decorrente de umidade ascensional, consequência da capilaridade dos materiais com o solo úmido e/ou encharcado.

Identifica-se ainda, que a grande maioria das manifestações indicadas são originadas pela falta de impermeabilização, principalmente do contado do solo onde o edifício está assentado com a base da edificação, podendo o solo estar saturado ou com umidade elevada, possibilitando a permeabilidade da água com os vazios dos materiais.

Com todos os focos identificados e analisados e segundo a metodologia abordada constatou-se o grau de risco, sendo todos os focos classificados como risco mínimo, onde o dano causado tem prejuízos pequenos e apenas à estética da edificação. Logo é possível prever o não comprometimento de dano à estrutura sem ocorrência de falhas, já que todas as manifestações patológicas identificadas se dão por meios superficiais. 
F-IDENTIFICAÇÃO DA FIGURA X-NUMERO DA FIGURA NO
CORPO DO TEXTO

LEGENDA

- Mancha

- Goteira
Mofo e Bolor

- Eflorescência

- Saponificação

Desagregamento da Pintura

Bolhas

- Destacamento da Cerâmica

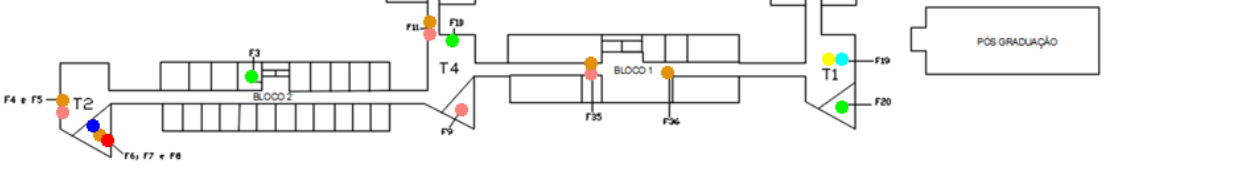

ESQUEMATIZAÇÃO DA PLANTA BAIXA $1 \circ$ PAVIMENTO
SEM ESCALA

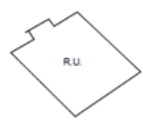

Figura 3 - Esquematização da planta baixa $1^{\circ}$ pavimento.

FX FX
F-IDENTIFICACÃO DA FGUURA
X-NUMERO DA FIGURA NO

LEGENDA

- Mancha

Goteira
Mofo e Bolor

Eflorescência

Saponificação

Bolhas

Destacamento da Cerâmica

TX-Torre X
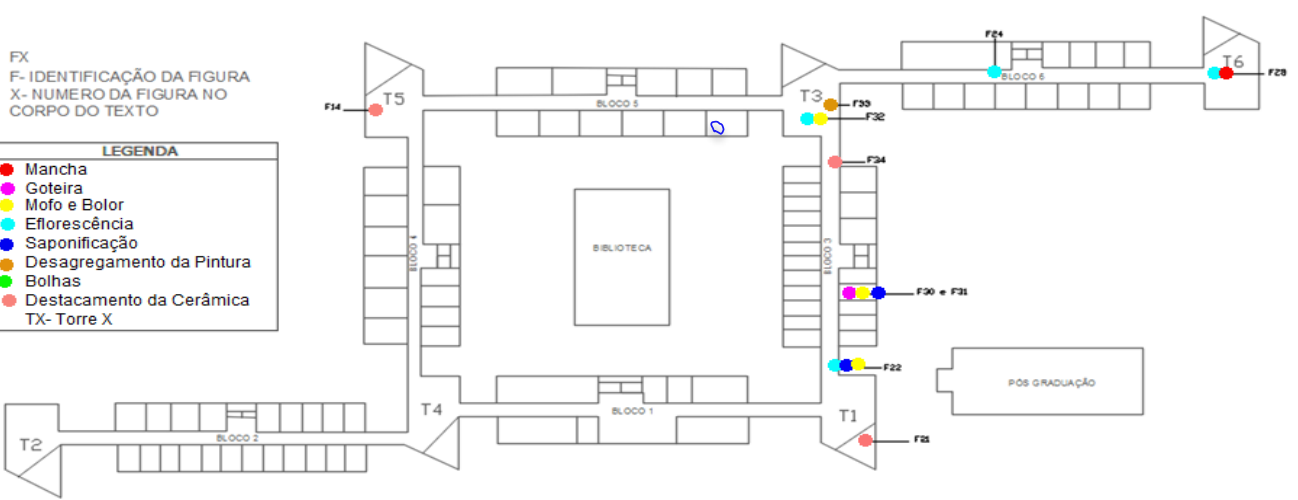

ESQUEMATIZAÇÃO DA PLANTA BAIXA SEM ESCALA

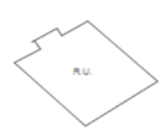

Figura 4 - Esquematização da planta baixa $2^{\circ}$ pavimento.

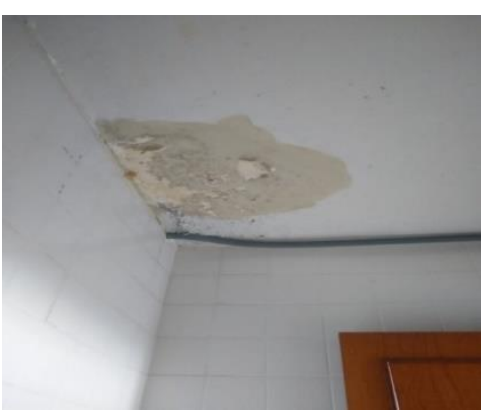

Figura 5 - Saponificação e manchas por umidade acidental.

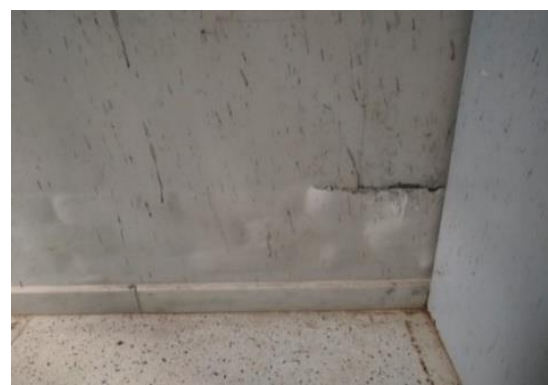

Figura 7 - Bolhas e desagregamento.

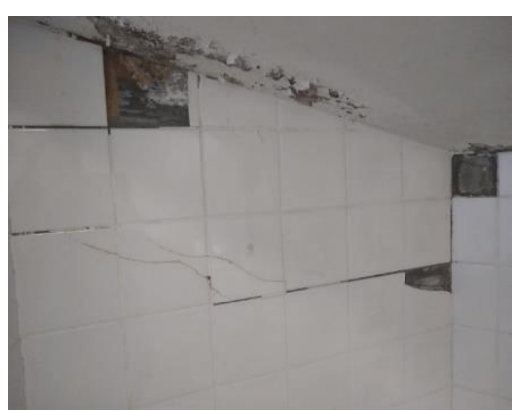

Figura 6 - Destacamento da cerâmica.

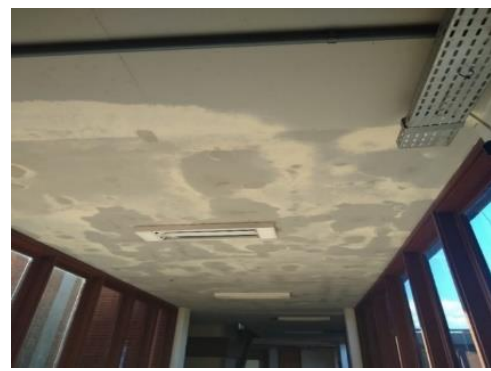

Figura 8 - Eflorescência e manchas. 


\section{Conclusões}

Os problemas referentes a umidade estão presentes em todas as fases da vida de uma edificação, indo desde o projeto até a manutenção da mesma. As patologias de umidade não são de fácil controle, assim, devem ser identificados os pontos e causas com exatidão, para a melhor correção da patologia.

A umidade nas construções pode diminuir a vida útil da estrutura e altos prejuízos financeiros. Por isso a importância dos estudos patológicos das edificações em uso. As manifestações patológicas identificadas neste estudo, no edifício da Universidade Federal de São João Del Rei Campus Alto Paraopeba, são ocasionadas pela umidade e estão acarretando prejuízos de caráter econômico, funcional, de desempenho, estéticos e estrutural.

Assim, tomando todas essas considerações, entende-se a importância de uma vistoria adequada, para a identificação da manifestação de patologias, quanto para a manutenção e/ou reparos, com finalidade de proteção do edifício, acarretando em aumento de sua vida útil.

\section{Referências Bibliográficas}

INSTITUTO BRASILEIRO DE AVALIAÇÕES E PERÍCIAS DE ENGENHARIA -IBAPE (2012). Norma de inspeção predial nacional. São Paulo.

INTERNATIONAL ORGANIZATION FOR STANDARDZATION -ISO (2008). General Principles on the Design of Structures for Durability. ISO 13823. Geneva: ISO/TC.

BOLINA, F. L.; TUTIKIAN, B. F.; HELENE, P. R. L. (2019). Patologias de Estruturas. Editora Oficina de Textos.

CECHINEL, B. M.; VIEIRA, F. L.; MANTELLI, P.; TONEL, S. Infiltração em alvenaria estudo de caso em edifício na grande Florianópolis. Disponível em: file://C:/Users/marin/Downloads/70-56-1-PB.pdf. Acesso: 22 de março de 2021.

LERSCH, I. M. (2003). Contribuição Para a Identificação dos Principais Fatores de degradação em edificações do patrimônio cultural de Porto Alegre. Dissertação (Mestrado em Engenharia Civil) - Universidade Federal do Rio Grande do Sul. Porto Alegre - RS.

OLIVEIRA, D. (2013). Levantamento de causas de patologias na construção civil. Monografia (Graduação em Engenharia Civil) - Universidade Federal do Rio de Janeiro. Rio de Janeiro - RJ.

POSSAN, E.; DEMOLINER, C. A. (2013). Desempenho, Durabilidade e Vida Útil das Edificações: Abordagem Geral. Revista Técnico Científica do CREA-PR. $1^{\circ}$ ed. p. 1-14.

QUERUZ, F. (2007). Contribuição para identificação dos principais agentes e mecanismos de degradação em edificações da Vila Bélgica. Dissertação (Mestrado em Engenharia Civil) - Universidade Federal de Santa Maria. Santa Maria - RS.

RIGHI, G. V. (2009). Estudo dos Sistemas de Impermeabilização: Patologias, Prevenções e Correções Análise de casos. Dissertação (Mestrado em Engenharia Civil) - Universidade Federal de Santa Maria. Santa Maria - RS.

SCHEIDEGGER, G. M.; CALENZANI, C. L. (2019). Patologia, recuperação e reparo das estruturas de concreto. Revista Científica Multidisciplinar Núcleo do Conhecimento. Ano 04, Ed. 03, Vol. 05, pp. 68-92.

SCHÖNARDIE, C. E. (2009). Análise e tratamento das manifestações patológicas por infiltração em edificações. Monografia (Graduação em Engenharia Civil) - Universidade Regional do Noroeste do Estado do Rio Grande do Sul. Porto Alegre - RS.

SOUZA, V.; RIPPER, T. (1998). Recuperação e Reforço de Estruturas de Concreto. Editora: Pini. São Paulo.

SOUZA, M. F. (2008). Patologias ocasionadas pela umidade nas edificações. Monografia (Graduação em Engenharia Civil) - Universidade Federal de Minas Gerais. Belo Horizonte - MG.

TUTIKIAN, B.; PACHECO, M. (2013). Boletín Técnico - Inspección, Diagnóstico y Prognóstico en la Construcción Civil. ALCONPAT. Mérida - México. 